\title{
Dimensional and Shape Accuracy of Foundry Patterns Fabricated Through Photo-Curing
}

\author{
Paweł ZMARZŁY, Tomasz KOZIOR, Damian GOGOLEWSKI
}

\begin{abstract}
This paper deals with the potential use of the PolyJet Matrix (PJM) technology and digital materials to fabricate foundry patterns. The primary purpose of the study was to assess the dimensional and shape accuracy of additively manufactured objects by determining the draft angle as well as the roundness, waviness and roughness parameters. The experiments were conducted for cylindrical samples printed using VeroWhite liquid polymer resin. The analysis focused on the relationship between the build direction and the geometry and surface finish of prints. Three different orientations, i.e. $0^{\circ}, 45^{\circ}$ and $90^{\circ}$, were considered. The surface texture analysis involved comparing the statistical, graphical and numerical data, including calculation results obtained with the wavelet transform method. The findings confirm that the build direction has a significant effect on the dimensional and shape accuracy of prints and that the PJM technology can be used to fabricate precise foundry patterns, especially in investment (lost-wax) casting.
\end{abstract}

Keywords: additive manufacturing technologies; foundry pattern; PJM; technological heredity; wavelet transform; waviness deviations

\section{INTRODUCTION}

The innovations and advancements in the foundry industry have led to increasingly high quality castings. The most important factor affecting the dimensional and shape accuracy of castings is the proper preparation of patterns. Complex analysis of their geometry and surface finish, e.g. roundness and roughness, is crucial since they have a direct influence on the quality of final products (castings) [1-5].

The intensive development of manufacturing processes implies the possibility of their application in a lot of industry branches, e.g. in the aircraft industry, in the automotive industry, construction of components which work under constant loads [6-8] and in textile production [9]. Particularly important due to the efficiency of the manufacturing process is the application of additive technology to build foundry patterns, allowing immediate fabrication of the "first cast sample" [10-12]. It allows to assess the casting technology and for immediate implementation of changes to final patterns. The first sample allows assessing the proper construction, mechanical properties of the elements and dimensional shape accuracy. Moreover, it allows minimising the costs associated with heat treatment and evaluating of foundry accuracy, technology and standards. The use of additive technology allows for immediate construction of the model directly from a three-dimensional CAD file [13-15] (stl, amf) and performs the first piece without involving high qualified personnel.

In the case of conventional production methods of foundry patterns any modification of patterns results in expensive, time-consuming operations, aimed to obtain the technological and dimensional requirements. Additive technologies allow building models within few hours and eliminating many of previously mentioned problems. The main factor which causes that customer decided to choose selected foundry is time of production of the first sample cast. Current research results related to the application of additive technologies in foundry industry do not describe the processes and problems in details.

After analysing the current state of art it can be noted that the adaptation of additive technology for the construction of foundry patterns was described in the following papers [15-17]. However, these works do not describe in a comprehensive way the influence of technological parameters on the dimensional and shape accuracy, mechanical and tribological properties

The application of PolyJet Matrix technology to manufacture elements whose shape allows producing them by casting method was presented in [12]. Authors used two types of materials FullCure 720, VeroWhite and 3D printer, Stratasys, Objet 350. The study examined the influence of technological parameters in an assembly of cooperating machine parts. However, the paper does not describe the application of additive technology in casting processes.

In paper [13] authors described the application of DODJET technology to build a foundry pattern of art medal. This method is technically similar to PolyJet Matrix technology. Liquid polymer resins are used to build models in both methods. To produce the model of the medal BlueCast TM material was used, which is characterised by thermoplastic properties and low coefficient of expansion. Because of the low melting point, it can be used in lost material method, without producing any contaminants. The model which was made by DODJET technology had been used to produce the wax model enabling to perform final cast using the lost-material method. However, in the work, authors did not examine the impact of additive technology parameters on dimensional and shape accuracy of elements.

Moreover, additive technologies were used in precise casting using the lost material method [15]. The authors used fused deposition modelling (FDM), multi jet modelling (MJM) and selective laser sintering (SLS) technologies to build dental prostheses. The paper compares above mentioned technologies due to the shrinkage of the material and quality of the technological layer. The research result showed that the samples made by FDM technology were characterised by the highest values of surface roughness parameters. The lowest value of roughness parameters was in samples manufactured by SLS technology. The authors also demonstrated that the build direction significantly affects the surface roughness.

There were also researches related to application of other additive technologies to build foundry patterns. In paper [16] authors used ZCast technology to build foundry 
patterns. They analysed the impact of technological parameters on the geometrical structure of the surface.

Example of the use of additive technology to build foundry patterns was presented in [17]. The authors used RFP (rapid freeze prototyping) technology, which was based on the FCP (freeze cast process) technology. In the paper was determined the effect of basic technological parameters, i.e. the thickness and width of building layer, scanning speed, spray parameters on the dimensions of the layers, the parameters of the surface texture and the accuracy of the typical casting elements. This technology is one of the most environmentally friendly because of the use of pure ceramic material (based on water).

Technology based on the above mentioned method is FEF (freeze forms of extrusion fabrication) [18]. In this technique, the material used to build elements is in a form of mixture of ceramic powder and water in various proportions $\left(\mathrm{Al}_{2} \mathrm{O}_{3}\right)$. The authors of the presented study have examined the impact of technological parameters, i.e. the nozzle velocity, the temperature in the working chamber and the geometrical dimensions of the distributed material on the accuracy of thin-walled components and their strength.

The application of almost all most important additive manufacturing technologies has also been described in works [19-21], where authors presented the advantages and disadvantages of key additive technologies and different types of materials. Furthermore, they presented directions for further research. However, there is no reference to casting drafts or the quality of the casting surface which is key parameter in precision casting.

It is known that the dimensional and shape accuracy of foundry patterns is very important, because the surface irregularities of foundry patterns will impact the final product quality. These phenomena are caused by so-called "technological heredity".

High dimensional and shape accuracy of foundry patterns is required as early as the design stage. However technologists need to provide patterns which are easy to remove from casting molds. Therefore, it is necessary to add casting drafts and provide proper surface roughness. An angle deviation from the vertical plane of the model is called the casting drafts. They are used in order to easily remove the patterns or core from the mold, which prevents destroying of mold edge. Therefore, correct preparation of casting drafts is a key issue. Another important factor affecting the product quality is condition of surface layer. Primary profile determines real state of surface of manufactured product. These irregularities have specific impact on different exploitation parameters of manufactured products.

Due to the above mentioned facts, this paper describes an alternative way to fabricate foundry patterns. The results included in this paper may be used in the future in almost all casting methods, kinds of foundry, which require rapid production of precise foundry patterns, especially using lost material method and sand molds. The comprehensive analysis allows for full-functional application of PJM technology in the industry and it may be helpful for casting technologists and companies manufacturing the foundry patterns. The results of this paper may improve the quality of final products and speed production up.

\section{MATERIALS AND METHODS}

As the findings of this study may be of use to engineers in the foundry industry, the samples were designed in accordance with some of the requirements for patterns used in different casting processes. The cylindrical samples used in the experiments had a draft of $1^{\circ}$, as recommended by the current casting standards. The primary aim of the study was to assess whether the photo-curing technology can be used to build foundry patterns. The analysis focused on the dimensional and shape accuracy of prints and their surface texture. Different build directions were taken into consideration. The samples were fabricated at predetermined process parameters.

\subsection{PJM Technology}

The PolyJet Matrix (PJM) technology, based on photosensitive liquid polymerization, is one of the most accurate rapid prototyping methods. The printing process consists of the layer-by-layer deposition of liquid resin to create a solid object. The material is jetted from a piezoelectric print heads on the printer build tray into thin, horizontal and successive cross-sections, cured with ultraviolet (UV) light. The UV radiation initiates the polymerization process. In the PJM technology, the primary factors having a direct influence on the process accuracy and the mechanical properties of the objects created are the build direction and the layer thickness. Elements fabricated through additive manufacturing exhibit strong structural anisotropy, which affects their dimensional and shape accuracy. When single materials are used, the minimum layer thickness in this method is $0.016 \mathrm{~mm}$; in the case of digital materials, it is $0.03 \mathrm{~mm}$ [13].

The PJM technology employs two types of materials: model material and support material. Once the printing is completed, the support material is removed by applying a chemical bath or a water jet. An important advantage of the PJM technology is that several materials can be mixed to create a new one so that the resulting material will have physical and chemical properties completely different from those of the raw materials. This method is also suitable to overprint materials differing in colour or mechanical properties. Finally, because of the low melting point of the model materials, the PJM technology is appropriate to make foundry patterns, particularly for lost wax casting.

\subsection{Samples}

The samples were fabricated using the PJM technology with a Connex Objet350. The printing was performed at the Laboratory of Unconventional Manufacturing Technology of the Kielce University of Technology. The foundry patterns were designed in CAD software (SolidWorks). The printing material was VeroWhite resin, a photosensitive liquid polymer. The mechanical properties of the material are provided in Tab. 1.

All the samples were created with a predetermined layer thickness of $0.03 \mathrm{~mm}$ in the 'Digital Material' mode. Because of the anisotropy in mechanical properties caused by the build orientation [22-24], which is typical of 
additive manufacturing technologies used to fabricate plastic objects, the experiments were conducted for samples virtually oriented on the build tray in three different directions, i.e. at an angle of $0^{\circ}, 45^{\circ}$ or $90^{\circ}$. The samples were cylindrical in shape with a height of $25 \mathrm{~mm}$ and a base diameter of $20 \mathrm{~mm}$ (Fig. 1a). The solid models with support material are shown in Fig. 1b; the top and side measurement planes are marked I and II, respectively.

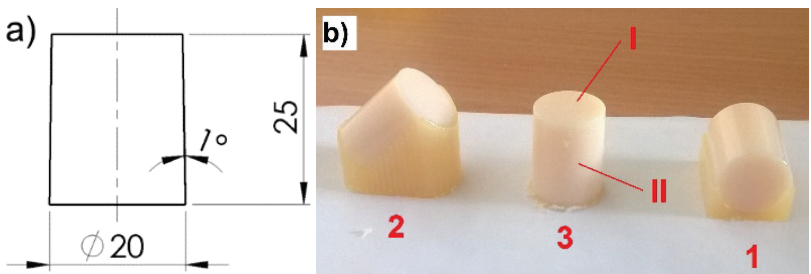

Figure 1 a) Sample drawing b) Solid models with support material

Table 1 Mechanical properties of VeroWhite material [31]

\begin{tabular}{|c|c|c|c|}
\hline Mechanical properties & Value & Unit & Standard \\
\hline Modulus of elasticity & 2495 & $\mathrm{MPa}$ & ASTM D-638 \\
\hline Tensile strength & 49.8 & $\mathrm{MPa}$ & ASTM D-638 \\
\hline Flexural strength & 74.6 & $\mathrm{MPa}$ & ASTM D-790 \\
\hline Izod Notched Impact & 24.1 & $\mathrm{~kJ} / \mathrm{m}^{2}$ & ASTM D-256 \\
\hline Shore hardness & 83 & Scale D & Scale D \\
\hline
\end{tabular}

\subsection{Draft Angle}

Proper draft or taper allowance on vertical surfaces of a pattern is necessary for easy pattern removal in both conventional and unconventional casting. Too large a draft angle may result in the occurrence of hot spots due to uneven cooling, heavier castings, castings with worse surface finish, or a damaged mould cavity. So far there has been hardly any research concerning the accuracy of draft allowance for additively manufactured foundry patterns. The measurements were performed at the Laboratory of Computerised Measurement of Geometric Quantities of the Kielce University of Technology using a Zeiss PRISMO Navigator coordinate measuring machine. A VAST Gold S-ACC (super accuracy) probe was selected for the tests. The other sensors available are the RDS articulating probe and the optical probe. The draft angle of the samples was determined at a measuring range of 900 $\mathrm{mm}[X], 1200 \mathrm{~mm}[Y], 700 \mathrm{~mm} \mathrm{[Z]} \mathrm{and} \mathrm{a} \mathrm{length}$ measurement error of $0.9+L / 350 \mu \mathrm{m}$.

\subsection{Roundness and Waviness}

Roundness is one of the most important parameters defining the accuracy of cylindrical elements. Roundness profile analysis was conducted for the additively manufactured cylindrical samples to determine defects resulting from the layer-wise nature of the photopolymerization process. Since in some cases the roundness data were not sufficient, it was necessary to perform detailed waviness analysis [26].

Roughness was measured along a generatrix and around the face. The sample geometry was characterised on the basis of roundness and waviness profiles.

The roundness and waviness data for the samples created using the PJM technology were obtained with a Taylor Hobson Talyrond 365. The operating principle of the machine is based on the radial method. The Talyrond
365 , equipped with a gauge head $(0.08 \mathrm{~mm}$ range, $1.3 \mathrm{~nm}$ resolution) and powerful Ultra roundness software is an instrument offering high accuracy measurement. The roundness and waviness profiles were measured at halfheight, i.e. $12.5 \mathrm{~mm}$. The parameter determined in the experiments for roundness and waviness was $R O N t$; it was obtained in the ranges of 2-15 upr (undulations per revolution) and 16-50 upr, respectively. The primary profiles were filtered using a Gaussian filter.

\subsection{Roughness}

The 3D surface texture measurement was carried out using a Talysurf CCI. The non-contact optical metrological tool has a vertical resolution of up to $0.01 \mathrm{~nm}$ and a horizontal resolution of up to $0.33 \mu \mathrm{m}$. From the literature on the surface texture of additively manufactured elements, it is evident that their surface quality differs from that reported for conventionally machined elements [25]. The complex surface texture analysis was based on the selected 3D roughness parameters, i.e. $S a, S q$, $S s k$ and $S k u$, which provide information on the surface properties of objects, especially resistance to friction and abrasive wear. Sa (arithmetical mean height) is the most common parameter used to assess surface roughness in different manufacturing processes. Sku (kurtosis) defines the sharpness of the probability density of a surface, i.e. the number of high peaks and low valleys. When the height distribution is normal, $S k u=3$. Ssk (skewness) is another roughness parameter, similar to $S k u$. Positive $S s k$ indicates the predominance of peaks, while negative $S s k$ suggests the predominance of valleys.

The surface texture analysis involved applying the wavelet transform method. Developed at the end of the 20th century, the procedure is now commonly used for signal decomposition in many fields of science. The method has the undoubted advantage of analysing signals with non-periodic irregularities and determining the location of sudden changes. The wavelet transform method is an ideal tool to analyse the surface texture.

Wavelet transform analysis is based on mother wavelets. As mother wavelets differ in properties, it is important that appropriate wavelets be selected for signal analysis and this can be done statistically [27]. Some mother wavelets used in signal analysis are able to improve image resolution or isolate and identify patterns that cannot be detected otherwise [28].

In signal analysis, a two-dimensional wavelet transform is used to divide the original signal into four at each level of decomposition. The approximation coefficient and the detail (horizontal, vertical and diagonal) coefficients provide information from different frequency bands. Approximations are high-scale low-frequency components of the original signal, while details are lowscale high-frequency components. At each level of decomposition, the measured signal is increasingly smoothed [29]. 

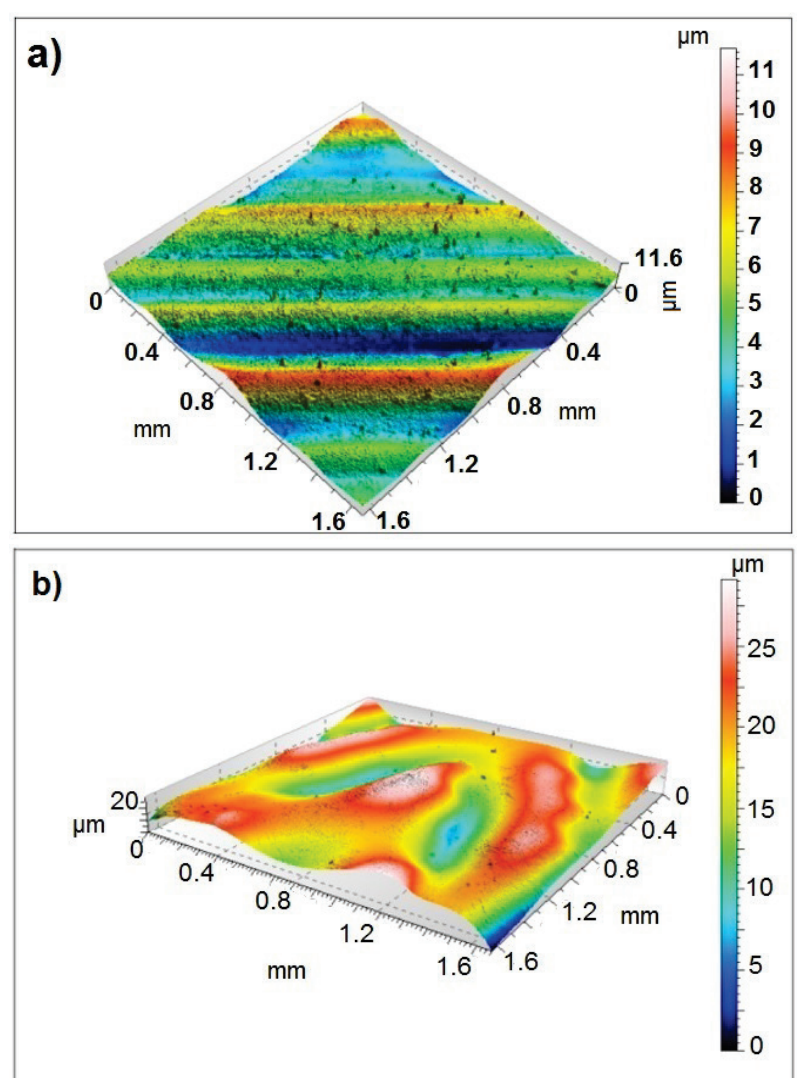

Figure 2 Variant $1\left(0^{\circ}\right)$ Isometric view of surface roughness a) top plane b) slant plane
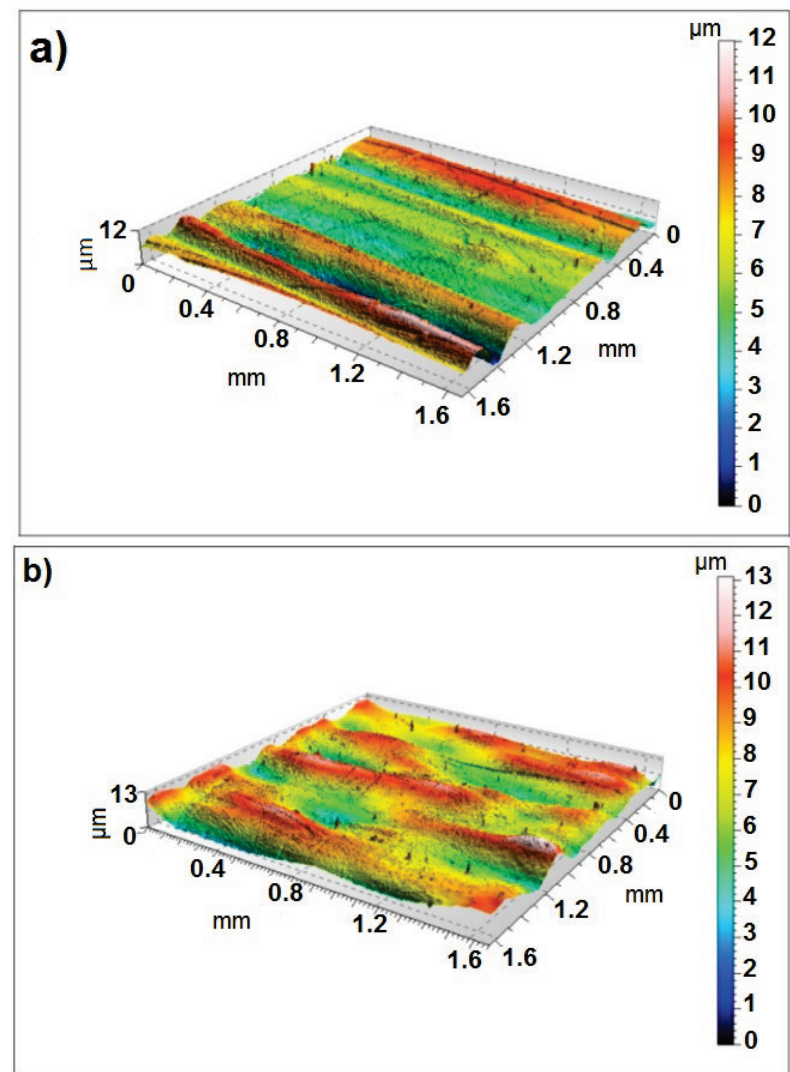

Figure 3 Variant $2\left(45^{\circ}\right)$ Isometric view of surface roughness a) top plane b) slant plane

\section{RESEARCH RESULT AND DISCUSSION}

The sample models were virtually placed on the build tray in three different orientations: $0^{\circ}$ (No. 1), $45^{\circ}$ (No. 2 ) and $90^{\circ}$ (No. 3). For each type of location were prepared five pieces of samples marked a-e. Figs. 2-4 show examples of isometric views of surface roughness for the top and the slant plane.

The cylindrical samples used in the experiments had a draft of $1^{\circ}$ (see Fig. 1a), as recommended by the current casting standards. Furthermore, in foundry industry it is desired to produce elements with as low as possible roundness and waviness deviation. Similarly is for the surface texture parameters e.g. $S a, S q$.
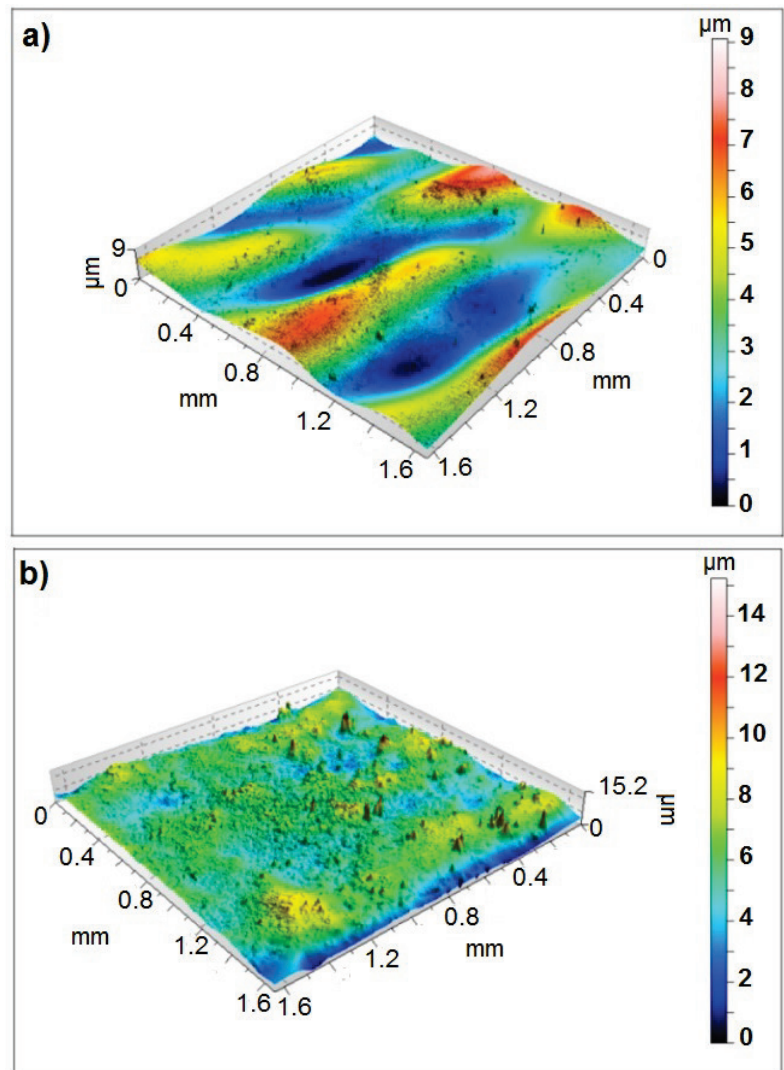

Figure 4 Variant $3\left(90^{\circ}\right)$ Isometric view of surface roughness a) top plane b) slant plane

\subsection{Draft Angle}

The research results of the draft angle are shown in Tab. 2, where the symbol $\bar{x}$ is mean value and $s$ is the mean deviation.

\begin{tabular}{|c|c|c|c|c|c|c|c|c|}
\hline \multicolumn{2}{|c|}{$\begin{array}{c}\text { Sample } \\
\text { No. }\end{array}$} & \multirow{2}{*}{$\frac{\text { Angle, }{ }^{\circ}}{1.021}$} & \multicolumn{2}{|c|}{$\begin{array}{c}\text { Sample } \\
\text { No. }\end{array}$} & \multirow{3}{*}{$\begin{array}{c}\text { Angle, }^{\circ} \\
0.876\end{array}$} & \multicolumn{2}{|c|}{$\begin{array}{c}\text { Sample } \\
\text { No. }\end{array}$} & \multirow{2}{*}{$\begin{array}{r}\text { Angle, }{ }^{\circ} \\
0.982\end{array}$} \\
\hline \multirow{7}{*}{1} & $\mathrm{a}$ & & \multirow{7}{*}{2} & $a$ & & \multirow{7}{*}{3} & $\mathrm{a}$ & \\
\hline & $\mathrm{b}$ & 1.005 & & $\mathrm{~b}$ & & & $\mathrm{~b}$ & 0.989 \\
\hline & $\mathrm{c}$ & 1.023 & & $\mathrm{c}$ & 0.979 & & $\mathrm{c}$ & 1.009 \\
\hline & $\mathrm{d}$ & 1.017 & & $\mathrm{~d}$ & 0.992 & & $\mathrm{~d}$ & 1.004 \\
\hline & $\mathrm{e}$ & 1.031 & & e & 0.891 & & $\mathrm{e}$ & 0.985 \\
\hline & $\overline{\bar{x}}$ & 1.020 & & $\bar{x}$ & 0.947 & & $\overline{\bar{x}}$ & 0.994 \\
\hline & $\mathrm{S}$ & 0.009 & & $\mathrm{~S}$ & 0.059 & & $\mathrm{~s}$ & 0.012 \\
\hline
\end{tabular}

The results of measurements of draft angle showed that orientation of the samples on the virtual platform impacts the value of the angle. In the case of samples No. 1, the mean measured angle value was equal to $1.02^{\circ}$ and it is greater than the expected nominal value. For the rest of the samples obtained values were less than assumed value. The highest dimensional deviation was achieved for samples 
No. 2. $\left(45^{\circ}\right)$. The relative error was more than $5 \%$. In the case of this type of orientation mean value of draft angle was equal to $0.947^{\circ}$.

\subsection{Surface Texture}

Surface texture components have direct impact on dimensional and shape accuracy of manufactured foundry patterns and thus affect the quality of final products. The form error (roundness deviation) and waviness deviation measurements have been carried out using non-reference method, where the measuring head moves along the perimeter of the sample. 3D roughness parameters were measured on the top plane and the slant plane of foundry patterns. Additionally, to evaluation the surface roughness the wavelet analysis has been applied.

\subsubsection{Roundness and Waviness}

The roundness and waviness measurement results are shown in Tab. 3.

Table 3 Roundness and waviness data

\begin{tabular}{|c|c|c|c|c|c|c|c|c|c|c|c|}
\hline \multirow{2}{*}{\multicolumn{2}{|c|}{$\begin{array}{c}\text { Sample } \\
\text { No. }\end{array}$}} & \multicolumn{2}{|c|}{$R O N t, \mu \mathrm{m}$} & \multirow{2}{*}{\multicolumn{2}{|c|}{$\begin{array}{c}\text { Sample } \\
\text { No. }\end{array}$}} & \multicolumn{2}{|c|}{$R O N t, \mu \mathrm{m}$} & \multirow{2}{*}{\multicolumn{2}{|c|}{$\begin{array}{c}\text { Sample } \\
\text { No. }\end{array}$}} & \multicolumn{2}{|c|}{$R O N t, \mu \mathrm{m}$} \\
\hline & & \multirow{2}{*}{$\begin{array}{c}2-15 \\
\text { upr } \\
193 \\
\end{array}$} & \multirow{2}{*}{$\begin{array}{c}16- \\
50 \\
\text { upr } \\
70\end{array}$} & & & \multirow{2}{*}{$\begin{array}{c}2-15 \\
\text { upr }\end{array}$} & \multirow{2}{*}{$\begin{array}{c}16- \\
50 \\
\text { upr } \\
74\end{array}$} & & & \multirow{2}{*}{$\begin{array}{r}2-15 \\
\text { upr } \\
52\end{array}$} & \multirow{2}{*}{$\begin{array}{c}16- \\
50 \\
\text { upr } \\
25\end{array}$} \\
\hline \multirow{7}{*}{1} & $\mathrm{a}$ & & & \multirow{7}{*}{2} & $\mathrm{a}$ & & & \multirow{7}{*}{3} & $\mathrm{a}$ & & \\
\hline & $\mathrm{b}$ & 146 & 90 & & $\mathrm{~b}$ & 193 & 89 & & $\mathrm{~b}$ & 46 & 22 \\
\hline & $\mathrm{c}$ & 182 & 79 & & $\mathrm{c}$ & 208 & 92 & & $\mathrm{c}$ & 44 & 63 \\
\hline & $\mathrm{d}$ & 185 & 77 & & $\mathrm{~d}$ & 187 & 78 & & $\mathrm{~d}$ & 33 & 24 \\
\hline & $\mathrm{e}$ & 181 & 84 & & $\mathrm{e}$ & 205 & 91 & & $\mathrm{e}$ & 57 & 24 \\
\hline & $\overline{\bar{x}}$ & 178 & 80 & & $\overline{\bar{x}}$ & 196 & 85 & & $\bar{x}$ & 46 & 32 \\
\hline & $\mathrm{s}$ & 18 & 7 & & $\mathrm{~s}$ & 9 & 8 & & $\mathrm{~s}$ & 9 & 17 \\
\hline
\end{tabular}

Analysing the research results presented in Tab. 3 it can be concluded that the highest values of roundness and waviness deviation were obtained for samples manufactured at an angle of $45^{\circ}$, while the lowest deviations were obtained for angle of $90^{\circ}$. The roundness deviations for all types of measured samples were higher than the waviness deviations.

The values of measured deviations can result from the building process, especially from the layers application type. For the samples manufactured at an angle of $90^{\circ}$, layers were distributed along a generatrix of cylindrical surface. In this orientation manufacturing time is the longest, but roundness and waviness deviations have the smallest value. Considering the foundry patterns manufactured at an angle of $45^{\circ}$, manufacturing time is shorter compared to above mentioned type. However, in this case, the form errors are the greatest, which is closely related to the build direction, and the phenomena so-called "stair-step effect".

Analysing the mean square error calculated for the roundness deviation $R O N t$, it can be concluded that the samples printed at an angle of $90^{\circ}$ indicated the highest repeatability. Similar results have been obtained for samples No. 2. Meanwhile, the largest variance of the measuring results showed samples printed at $0^{\circ}$. Considering waviness deviations it can be concluded that the smallest values of mean deviation were calculated for samples manufactured at an angle of $0^{\circ}$, while the largest at an angle of $90^{\circ}$.
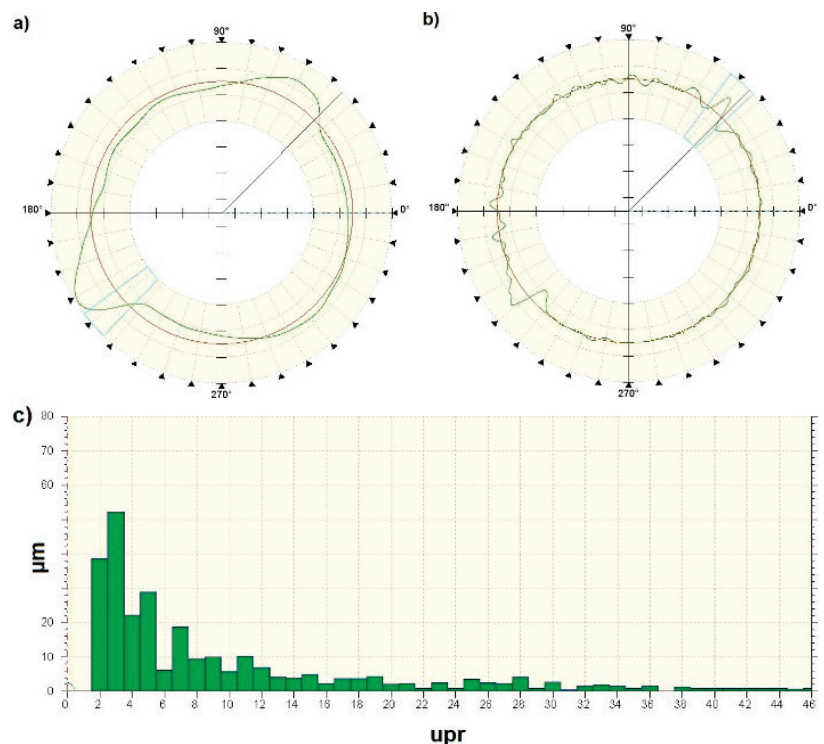

Figure 5 Variant 1 a) roundness deviation b) waviness deviation c) number of harmonics components
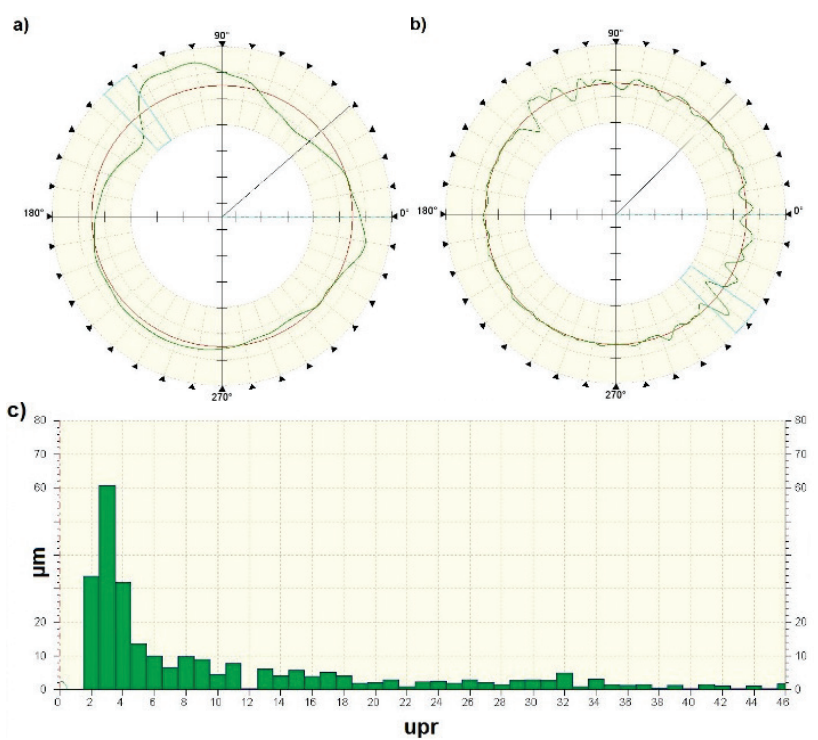

Figure 6 Variant 2 a) roundness deviation b) waviness deviation c) number of harmonics components
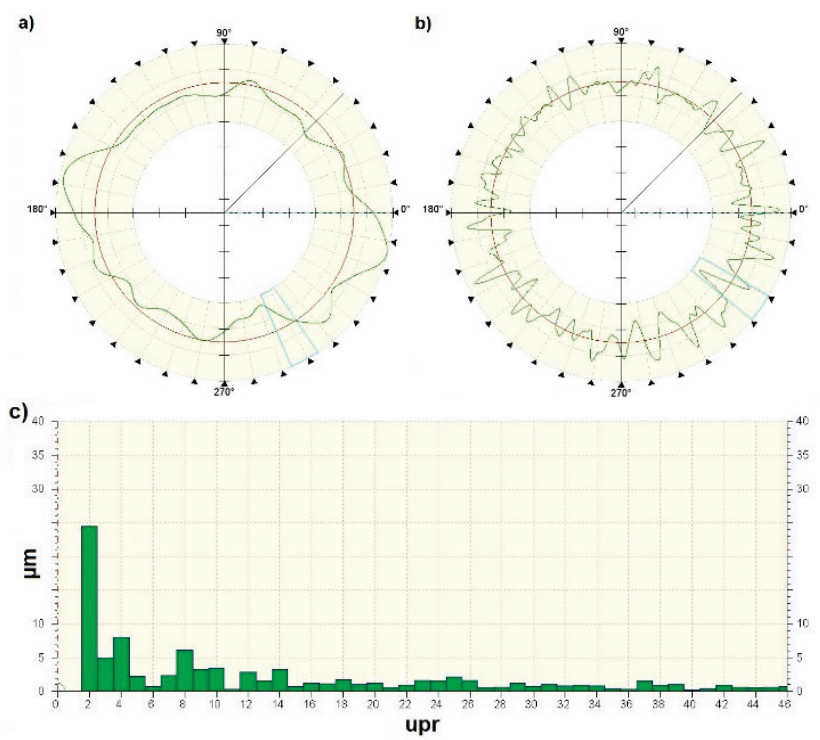

Figure 7 Variant 3 a) roundness deviation b) waviness deviation c) number of harmonics components 
Interesting results were obtained by harmonic analysis of measured profile, using Fast Fourier Transform. Considering the set of values of harmonic components of the cylindrical profile which are shown in Fig. 5 and Fig. 6 , the third harmonic is pre-dominant. This indicates that the manufactured foundry patterns are three-lobing deviations. While in the samples printed at $90^{\circ}$ the second harmonic components have the largest value (see Fig. 7). This allows to conclude that this kind of samples have oval shape.

To sum up, analysing the roundness and waviness measurements of foundry patterns it can be concluded that the most favourable results were obtained for printing angle equal to $90^{\circ}$. This angle should be used when we would like to produce accurate cylindrical elements. However, the less favourable results were achieved for samples printed at an angle of $45^{\circ}$.

\subsubsection{Surface Roughness}

The measurement results concerning surface roughness are shown in Tab. 4, where $s$ stands for mean deviation.

Table 4 Surface roughness parameters

\begin{tabular}{|c|c|c|c|c|c|c|c|c|c|}
\hline \multirow{2}{*}{\multicolumn{2}{|c|}{$\begin{array}{c}\text { Sample } \\
\text { No. }\end{array}$}} & \multicolumn{4}{|c|}{$\mathrm{I}$} & \multicolumn{4}{|c|}{ II } \\
\hline & & \multirow{2}{*}{$\begin{array}{c}S q, \\
\mu \mathrm{m}\end{array}$} & \multirow{2}{*}{$\begin{array}{c}S a, \\
\mu \mathrm{m}\end{array}$} & \multirow{2}{*}{$\begin{array}{l}\text { Ssk } \\
0.42\end{array}$} & \multirow{2}{*}{$\begin{array}{l}S k u \\
2.55\end{array}$} & \multirow{2}{*}{$\begin{array}{c}S q, \\
\mu \mathrm{m}\end{array}$} & \multirow{2}{*}{$\begin{array}{c}S a, \\
\mu \mathrm{m}\end{array}$} & \multirow{2}{*}{$\begin{array}{c}\text { Ssk } \\
0.18 \\
\end{array}$} & \multirow{2}{*}{$\begin{array}{l}S k u \\
2.59\end{array}$} \\
\hline \multirow{7}{*}{1} & $\mathrm{a}$ & & & & & & & & \\
\hline & $\mathrm{b}$ & 1.26 & 1.04 & 0.14 & 2.84 & 4.48 & 3.62 & -0.38 & 2.73 \\
\hline & $\mathrm{c}$ & 1.74 & 1.29 & -0.07 & 3.61 & 2.15 & 1.74 & 0.01 & 2.61 \\
\hline & $\mathrm{d}$ & 1.2 & 0.94 & 0.5 & 3.08 & 2.89 & 2.34 & -0.28 & 3.28 \\
\hline & $\mathrm{e}$ & 1.72 & 1.37 & 0.12 & 3 & 3.06 & 2.55 & -0.14 & 2.48 \\
\hline & $\bar{x}$ & 1.51 & 1.19 & 0.22 & 3.01 & 2.86 & 2.33 & -0.12 & 2.74 \\
\hline & $\mathrm{S}$ & 0.26 & 0.19 & 0.23 & 0.39 & 1.05 & 0.85 & 0.22 & 0.31 \\
\hline \multirow{7}{*}{2} & $\mathrm{a}$ & 1.49 & 1.17 & 0.01 & 2.94 & 1.18 & 0.95 & 0.09 & 2.73 \\
\hline & $\mathrm{b}$ & 1.78 & 1.41 & -0.1 & 2.89 & 1.69 & 1.36 & -0.31 & 2.99 \\
\hline & $\mathrm{c}$ & 1.7 & 1.38 & 0.38 & 2.65 & 1.4 & 1.12 & -0.14 & 3.16 \\
\hline & $\mathrm{d}$ & 1.83 & 1.51 & -0.09 & 2.64 & 1.74 & 1.41 & -0.2 & 2.73 \\
\hline & $\mathrm{e}$ & 1.95 & 1.61 & -0.08 & 2.49 & 1.67 & 1.3 & 0.26 & 3.39 \\
\hline & $\overline{\bar{x}}$ & 1.75 & 1.42 & 0.02 & 2.72 & 1.53 & 1.23 & -0.06 & 3 \\
\hline & $\mathrm{S}$ & 0.17 & 0.16 & 0.21 & 0.19 & 0.24 & 0.19 & 0.23 & 0.29 \\
\hline \multirow{7}{*}{3} & $\mathrm{a}$ & 0.99 & 0.83 & 0.25 & 2.41 & 1.26 & 0.96 & 0.04 & 4.3 \\
\hline & $\mathrm{b}$ & 1.1 & 0.91 & 0.02 & 2.31 & 2.09 & 1.61 & 0.18 & 4.16 \\
\hline & $\mathrm{c}$ & 1.28 & 1 & 0.31 & 3.39 & 1.15 & 0.8 & 0.69 & 7.7 \\
\hline & $\mathrm{d}$ & 1.2 & 1.03 & 0.13 & 2.08 & 1.48 & 1.18 & 0.12 & 3.32 \\
\hline & $\mathrm{e}$ & 1.22 & 1.01 & 0.12 & 2.58 & 1.48 & 1.14 & -0.07 & 4.02 \\
\hline & $\bar{x}$ & 1.16 & 0.95 & 0.16 & 2.55 & 1.49 & 1.14 & $\mathbf{0 . 1 9}$ & 4.7 \\
\hline & $\mathrm{s}$ & 0.12 & 0.09 & 0.11 & 0.5 & 0.36 & 0.3 & 0.29 & 1.72 \\
\hline
\end{tabular}

By analysing the surface topography shown in Figs. 24 it can be concluded that the surface character strongly depends on the location models on the virtual platform. In the case of the top plane illustrated in Figs. 2a, 3a and 4a "stairs effect" is strongly visible for samples manufactured at an angle of $0^{\circ}$ and $45^{\circ}$. Printing at $90^{\circ}$ to the building plane does not show this effect. In the case of slant planes, which are shown in Figs. 2b, $3 b$ and $4 b$ it should be noted that printing layers are more visible in samples Nos. 1 and 2.

After analysing the research results, it can be concluded that in the case of top plane (type I) $\mathrm{Sa}$ and $\mathrm{Sq}$ parameters the smallest values were obtained for samples No. 3, whereas the highest values were achieved for samples No. 2.

Mean values of these parameters were respectively: samples No. $3(S q=1.155 \mu \mathrm{m}, S a=0.953 \mu \mathrm{m})$, samples
No. 2. $(S q=1.749 \mu \mathrm{m} S a=1.416 \mu \mathrm{m})$. The study of the Ssk parameter values showed that the biggest skewness was reached for samples No. 1, what is caused by the occurrence of convex areas on surface. The lowest values were achieved for samples No. 2, what is caused by flattening peaks. These surfaces are characterised by greater number of valleys, which is characteristic for "stairstep effect" phenomena, which is typical for most additive technologies. Analysing the kurtosis parameter $(S k u)$ can be concluded that the roughness parameter values decreased with increasing of placement angle. So for the perfectly random surfaces kurtosis parameter reaches value equal to 3 , it can be concluded that the samples fabricated at an angle of $0^{\circ}$ (No. 1) have similar surface character, i.e. mean parameter value is equal to 3.014 .

By analyzing the surface topography parameters of slant plane it can be noted that $S a$ and $S q$ parameters reached the highest values for samples No. 1 ( $S a=2.332$ $\mu \mathrm{m}, S q=2.859 \mu \mathrm{m})$, and the parameter value decreased with increasing placement angle. Ssk parameter values were obtained for samples Nos. 1 and reached negative values, which indicate that slant planes surface is characterised by irregularities with flattening peaks. The slant planes of samples manufactured at an angle of $90^{\circ}$ to virtual platform (No. 3) are characterised by much sharper irregularities. The mean value of this parameter reached the positive value. The kurtosis value parameter $(S k u)$ for samples No. 1 reached value close to 3 , so it can be stated that the distribution of height surface is similar to normal distribution. Parameter value equal to 3 has been reached for samples No. 2. After analysing research results from Tab. 4, it can be concluded that the distribution of height surface curves for samples No. 3 has a more slender shape in comparison with samples Nos. 1 and 2, i.e. they are higher and narrower. By analysing the obtained values of 3D surface roughness parameters, it can be concluded that quality of surface layer satisfies the requirements for foundry industry.
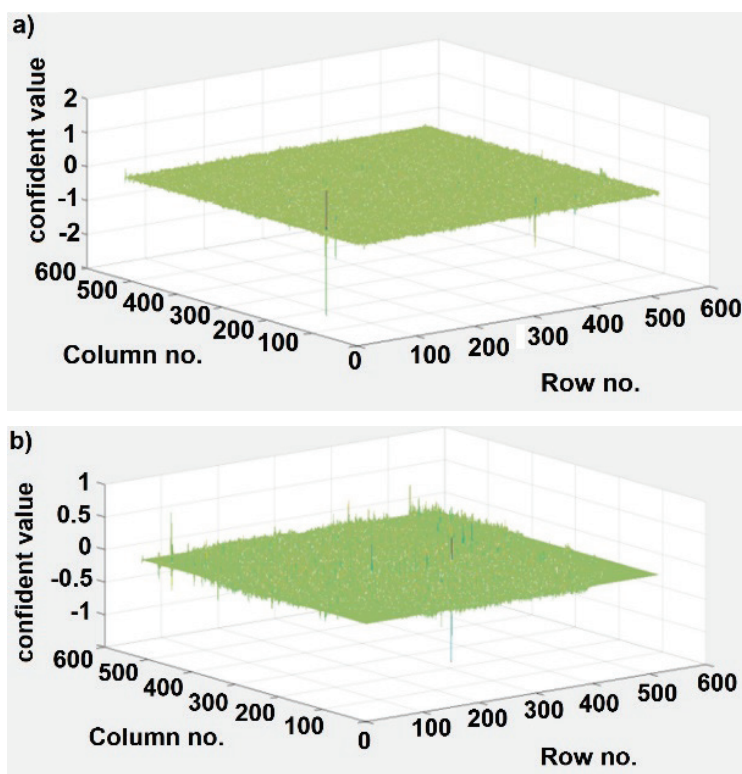

Figure 8 a) Wavelet vertical detail coefficients - the top plane b) Wavelet vertical detail coefficients - the slant plane

The study of the surface layer using wavelet transform aimed to determine characteristic areas on the elements 
surface. In that case, decomposition process has been carried out using mother wavelet $d b 12$. The research involved signal details created on the first level of analysis. Based on the research result it can be concluded that wavelet analysis had detected sudden change of coefficients values in detail signals. The isometric views which show the location of these changes are shown in Fig. 8. Fig. 8a shows wavelet vertical detail coefficients on the top plane (No. 1). In Fig. $8 \mathrm{~b}$ are shown wavelet vertical detail coefficients on the slant plane (No. 3).

According to [30], detail signals created at levels 1 and 2 of the decomposition contain only noise. The research results show that details created on the first level of decomposition contain specific information about signal. Therefore, signals cannot be treated as noise. This fact may indicate surface defects and may provide additional insight in the surfaces engineering design.

In order to confirm that detail coefficients contain characteristic information the statistical test of autocorrelation was conducted. The calculation results of Moran's statistic confirm that detail coefficients at the first level of decomposition cannot be treated as series of independent variables

\section{CONCLUSIONS}

The aim of this study was to assess the potential use of the PolyJet Matrix additive manufacturing technology to fabricate foundry patterns. The experiments involved determining the dimensional and shape accuracy of 3D prints according to the build direction, which required measuring the draft angle, roundness, and waviness and roughness. The results confirm that the dimensional and shape accuracy of foundry patterns has a considerable effect on the casting process and, in consequence, the geometry and surface quality of castings. This relationship is defined as 'technological heredity'.

The following are the general conclusions drawn from the experimental results:

1. The analysis of the $S q$ parameter, one of the most statistically significant roughness parameters, showed that the lowest values were reported for vertically oriented samples, i. e. ones printed at an angle of $90^{\circ}$ to the build tray plane. The build time in the $Z$ direction, however, was found to be the longest.

2. The parameters providing information on the nature of surface irregularities were the most useful to assess the accuracy of samples fabricated at an angle of $45^{\circ}$. The measurement results indicate irregularities with flattened peaks.

3. The most accurate representation of the nominal draft angle was achieved for the samples created at $90^{\circ}$.

4. The shortest build time was recorded for samples printed at an angle of $0^{\circ}$, because of the smallest number of layers.

5. The values of the surface roughness parameters obtained in the measurements of the draft angle suggest that the PJM technology is suitable for precision pattern making.

6. The measurement data concerning roundness and waviness indicate that geometrical deviations (e.g. threelobbing deviations) and insufficient surface finish of cylindrical samples printed at $0^{\circ}$ and $45^{\circ}$ may be attributable to the contact with support material throughout the printing process. The quality of samples oriented at $90^{\circ}$ was the highest because of the lack of support material. The results indicate the predominance of the second harmonic. From the measurement data concerning roundness and waviness, it can be concluded that the dominant values of harmonics were obtained at $n \epsilon<2 ; 15>$, with the range representing roundness. This is closely related to the build parameters, i.e. the layer thickness and the build direction as well as the area of contact of support material and its method of removal. The analysis of the higher range of harmonics $(n \epsilon<16 ; 50>)$, corresponding to surface waviness, reveals that the amplitudes are similar. This was confirmed by the parameter RONt determined in the range of 16-50 upr (undulations per revolution).

7. The surface texture of samples was analysed using the wavelet transform method. The analysis shows that it is possible to extract information concerning threedimensional signals. From the isometric views, it is clear that there are sudden changes in signal describing the surfaces. Details obtained at level 1 of the decomposition provide specific information about a signal so they cannot be treated as noise. They may indicate surface defects. This additional information can be used at the design stage.

8. The analysis of the experimental data shows that there is a direct influence of support material on the micro and macro geometries of prints. The photo-curing technology is reported to be well-suited to build geometrically accurate patterns, especially for investment casting.

9. The experiments described in this paper can be treated as preliminary studies to determine the uncertainty of measurement of additively manufactured casting patterns and moulds. Further research involving a wide range of elements, i.e. ones with different sizes and shapes, is required to assess the accuracy of the PJM technology and determine the upper and lower tolerance limits to be used at the design stage.

10. High dimensional and shape accuracy of foundry patterns is essential to obtain high quality castings. Imperfect patterns result in imperfect castings, for example, ones with surface irregularities. This relationship is called 'technological heredity'.

The research results presented in this paper are unique in that they concern the potential use of additive manufacturing technologies for the purposes of the foundry industry. This approach to pattern making is relatively new. Because of the complexity of additive manufacturing processes, this study is an introduction to larger research projects focusing on the potential use of additive manufacturing to fabricate foundry patterns. In the future, the authors intend to continue the research in this area by further investigating the relationship between the build parameters and the mechanical and surface properties of foundry patterns fabricated using different additive manufacturing methods.

\section{Acknowledgements}

The research presented in this paper was partially supported by the National Science Centre of Poland under the scientific work No. 2017/01/X/ST2/00155, entitled "Mathematical models of the impact assessment of selected 
parameters of the geometrical structure of active surfaces of rolling bearings on the level of generated vibration".

\section{REFERENCES}

[1] Adamczak, S. (2008). Measurement of surface texture. Form profiles, waviness and roughness, Warsaw, WNT.

[2] Whitehouse, D. J. (2011) Handbook of Surface and Nanometrology - second edition, Boca Raton, CRC PRESS. https://doi.org/10.1201/b10415

[3] Adamczak, S., Zmarzły, P., \& Stępień, K. (2016). Identification and analysis of optimal method parameters of the V-block waviness measurements. Bulletin of the Polish Academy of Sciences Technical Science, 64(2) 45-52. https://doi.org/10.1515/bpasts-2016-0037

[4] Thompson, A., Körner, L., Senin, N., Lawes, S., Maskery I., \& Leach, R., (2017) Measurement of internal surfaces of additively manufactured parts by X-ray computed tomography. Paper presented at $7^{\text {th }}$ Conference on Industrial Computed Tomography, Leuven, Belgium

[5] Adamczak, S. \& Zmarzły, P. (2017). Influence of raceway waviness on the level of vibration in rolling-element bearings. Bulletin of the Polish Academy of Sciences Technical Science, 64(2) 45-52. https://doi.org/10.1515/bpasts-2017-0059

[6] Bochnia, J. \& Błasiak, S. (2018). Fractional relaxation model of materials obtained with selective laser sintering technology. Rapid Prototyping Journal, (1) 1-11. https://doi.org/10.1108/RPJ-11-2017-0236

[7] Kundera, C., Martsynkowskyy, V., Gudkov, S., \& Kozior, T. (2017). Effect of rheological parameters of elastomeric ring materials on dynamic of face seals. Procedia Engineering, 177, 307-313. https://doi.org/10.1016/j.proeng.2017.02.230

[8] Puigoriol, J. M., Alsina, A., Salazar-Martin, A. G., GómezGras, G., \& Pérez, M. A. (2018). Flexural fatigue properties of polycarbonate fused-deposition modelling specimens. Materials \& Design, 155, 414-421. https://doi.org/10.1016/j.matdes.2018.06.018

[9] Kozior, T., Döpke, C., Grimmelsmann, N., Junger, I. J., \& Ehrmann, A. (2018). Influence of fabric pretreatment on adhesion of three-dimensional printed material on textile substrates. Advances in Mechanical Engineering, 10(8), 1-8. https://doi.org/10.1177/1687814018792316

[10] Chhabra, M. \& Singh, R. (2011). Rapid casting solutions: a review. Rapid Prototyping Journal, 17(5), 328-350. https://doi.org/10.1108/13552541111156469

[11] Coniglio, N., Sivarupan, T., \& El Mansori, M. (2018). Investigation of process parameter effect on anisotropic properties of 3D printed sand molds. International Journal of Advanced Manufacturing Technology, 94, 2175-2185. https://doi.org/10.1007/s00170-017-0861-5

[12] Jarco, A., Rzadkosz, S., Kroksz, J., Pabiś, R., Gil, A., Czekaj, E., Młodnicki, S., \& Ćwiklak, R. (2012). Technical and design study of the use of rapid prototyping technique to make an art casting of medal commemorating the 65th anniversary of the establishment of foundry research institute in Cracow. Prace Instytutu Odlewnictwa, 52(1) 55-70.

[13] Chen, Y. \& Zhezheng, C. (2011). Joint analysis in rapid fabrication of non-assembly mechanisms. Rapid Prototyping Journal, 17(6), 408-417. https://doi.org/10.1108/13552541111184134

[14] Krolczyk, G., Raos, P., \& Legutko, S. (2014). Experimental analysis of surface roughness and surface texture of machined and fused deposition modelled parts. Metrol. Meas. Syst., XXI(4), 759-770. https://doi.org/10.2478/mms-2014-0060

[15] Dikova, T., Dzhendov, D., Bliznakova, K., \& Ivanov, D. (2016). Application of 3D printing in manufacturing of cast patterns. Paper presented at VII International Metallurgical Congress MME in Ohrid, Macedonia.

[16] Chhabra, M. \& Singh, R. (2012). Obtaining desired surface roughness of castings produced using ZCast direct metal casting process through Taguchi's experimental approach. Rapid Prototyping Journal, 18(6), 458-471. https://doi.org/10.1108/13552541211272009

[17] Liu, Q., Sui, G., \& Leu, M. C. (2002). Experimental study on the ice pattern fabrication for the investment casting by rapid freeze prototyping (RFP). Computers in Industry, 48(3) 181197. https://doi.org/10.1016/S0166-3615(02)00042-8

[18] Li, M., Ghazanfari, A., Li, W., Landers, R. G., \&Leu, M. C. (2016). Modeling and analysis of paste freezing in freezeform extrusion fabrication of thin-wall parts via a lumped method. Journal of Materials Processing Technology, 237, 163-180. https://doi.org/10.1016/j.jmatprotec.2016.05.027

[19] Guo, N. \& Leu, M.C. (2013). Additive manufacturing: technology, applications and research needs. Frontiers of Mechanical Engineering, 8(3), 215-243. https://doi.org/10.1007/s11465-013-0248-8

[20] Campbell, I., Bourell, D., \& Gibson, I. (2012). Additive manufacturing: rapid prototyping comes of age. Rapid Prototyping Journal, 18(4), 255-258. https://doi.org/10.1108/13552541211231563

[21] Rokicki, P., Budzik, G., Kubiak, K., Bernaczek, J., Dziubek, T., Magniszewski, M., Nowotnik, A., Sieniawski, J., Matysiak, H., Cygan, R., \& Trojan, A. (2014). Rapid prototyping in manufacturing of core models of aircraft engine blades, Aircraft Engineering and Aerospace Technology, 86, 323-327. https://doi.org/10.1108/AEAT-10-2012-0192

[22] Adamczak, S., Zmarzły, P., Kozior, T., \& Gogolewski, D. (2017). Analysis of the dimensional accuracy of casting models manufactured by fused deposition modeling technology. Engineering Mechanics, 66-69.

[23] Kundera, C. \& Kozior, T. (2014) Research of the elastic properties of bellows made in SLS technology. Advanced Materials Research, 874, 77-81. https://doi.org/10.4028/www.scientific.net/AMR.874.77

[24] Bartkowiak, T., Lehner, J. T., Hyde, J., Wang, Z., Bue Pedersen, D., Norgaard Hansen, H., \& Brown, C. A. (2015). Multi-Scale areal curvature analysis of fused deposition surfaces. Paper presented at Achieving Precision Tolerances in Additive Manufacturing, Raleigh, North Carolina, USA (77-82). https://doi.org/10.13140/RG.2.1.3677.5441

[25] Nowakowski, Ł., Miko, E., \& Skrzyniarz, M. (2016). The analysis of the zone for initiating the cutting process of X37CrMoV51 steel. Engineering Mechanics, 426-429.

[26] Adamczak, S., Zmarzły, P., \& Janecki, D. (2015). Theoretical and Practical Investigations of V-Block Waviness Measurement of Cylindrical Parts. Metrology and Measurement Systems, 22(2), 181-192. https://doi.org/10.1515/mms-2015-0023

[27] Stępień, K., Makieła, W., Stoic, A., \& Samardzic, I. (2015). Defining the criteria to select the wavelet type for the assessment of surface quality. Tehnicki vjesnik, 22(3), 781784. https://doi.org/10.17559/TV-20140124110406

[28] Talu, S., Stępień, K., \& Caglayan, M. O. (2015). Topographic characterization of unworn contact lenses assessed by atomic force microscopy and wavelet transform. Microscopy Research and Technique, 78(11), 1026-1031. https://doi.org/10.1002/jemt.22580

[29] Gogolewski, D. (2018). The simulation method for the identification the surface irregularities. Engineering Mechanics, 253-256.

[30] Zawada-Tomkiewicz, A. (2010). Estimation of surface roughness parameter based on machined surface image. Metrology and Measurement System, 17(3), 493-504. https://doi.org/10.2478/v10178-010-0041-5 
[31] VeroWhite - FullCure830 (2018, July19) http://www.rptinnoteq.hu/media/Fullcure.pdf

\section{Contact information:}

Paweł ZMARZKY, PhD

(Corresponding author)

Kielce University of Technology,

Al. 1000-lecia P. P. 7, 25-314 Kielce, Poland

E-mail: pzmarzly@tu.kielce.pl

Tomasz KOZIOR, PhD

Kielce University of Technology,

Al. 1000-lecia P. P. 7, 25-314 Kielce, Poland

E-mail: tkozior@tu.kielce.pl

Damian GOGOLEWSKI, PhD

Kielce University of Technology,

Al. 1000-lecia P. P. 7, 25-314 Kielce, Poland

E-mail: dgogolewski@tu.kielce.pl 